\title{
Socioeconomic challenges and its inhabitable global illuminations
}

\author{
Rudrarup Gupta
}

Commercial Manager, Multifarious Projects Group, India; Overseas Reviewer, World Academy of Science and Technology, USA

(C) The Author, 2017. This article is published with open access at ARMG Publishing.

\begin{abstract}
This regimented Earth has an ubiquitous sagacity and it largely depends upon the generous people, who do lead this wide-ranging globe in a befitting manner. But all the countries are not extremely developed in this massive Earth. Some are truly developing in deed. Moreover, those countries do not have the civilized infrastructure so far. In other words, they do not have the destined educational backbone due to limited net work and some inappropriate movements, respectively. That is the reason why they are in the mouth of unavoidable socioeconomic challenges since long. Besides their societal sustainability are being gradually uncertain and they are coming below a poverty line. They depend on the natural resources. Otherwise, they do not have the promising options to maintain their social momentum as a hole. Moreover, social fund strikes all those environmental issues along with a massive environmental need. Therefore, both social fund and the needful agricultural development might restrict the socioeconomic issues and, on the contrary, it might ensure the national gravity of a country to make it developed from the perspective of enriching infrastructure and handsome economic affluence, respectively.
\end{abstract}

Keywords: economic paradigm, social stature, leader's role and social prospects.

JEL Classification: I1, I2, I3, J01.

\section{Introduction}

It is true that we are all society abiding. We are compelled to lead our life as per the social need and demand. But each one of us shall have to get rid of these undeniable issues as soon as possible. So that it shall be more engaging for all of us to step in an unblemished society, indeed, where we might have the destined facilities in a befitting manner. Issues are as follows.

Poverty. It is one of the determining factors for our entire population at all. They who are below poverty line considered as poor. The healthy percentage shall have to be maintained from the end of men, women and children, who will be above poverty line and they shall be accordingly promoted. As a result, the nation shall have the bright light of success and each one of us shall have the socioeconomic radiance very shortly.

Family income. It has the most decisive consequence. It is an absolute issue when the entire family income is not up to the mark. People do face versatile problems for the same. That is why an employment is absolutely essential for a family to be grown up.

Education. It is one of the prime attributes as per the present day scenario. Most of the people are not educated enough in some developing countries. In that case they are not considered as successful citizens from the view of socioeconomic backgrounds at all. So, education has an immense importance to reform their crucial societal stature within a short while. This is how any developing country might demand to be developed and, on the other hand, they shall be able to reduce the social obligation as well.

The health status. It is indeed very pivotal in all over the globe, as poor people are always deprived to opt for their expensive treatment. So, they are not able to touch the poverty line any more. But people do suffer from different diseases irrespective of their financial affluence. So, each one of us should have the same medical treatment if required.

Evaluation of skills. As per the present day statistics skillful people are easily entitled to touch the poverty line within a short while. People should acquire some very promising skills to sustain in their combative life such as communication skill, writing skill, interpersonal skill, presentation skill and so on. It is always assumed that, people, who do have those aforesaid skills, are socially developed and enriched. So all those socioeconomic challenges are not at all a big deal for them. 
Cultural conflict. Due to socioeconomic challenges, cultural conflict does take place and it is entirely harmful to adjust in that society any more. Everybody does follow the proverb "might is right". So, it is absolutely difficult for them to sustain together. Each culture should have the same culture for leading a society in an unblemished manner. As a result, equal right shall be distributed amongst them for the utmost societal virtuosity soon.

Lifestyle. Both poor and rich people do not cherish their life in a same platform. Poor fellows do have their limited resources and that is why they are not accepted as per their poverty line. On the other hand rich people do enrich through their unlimited resources and uncountable finance as well. So it might causes conflicts sometimes. Therefore as per my surmise both poor and rich people should have the different domain not only to earn but to contribute for their booming society [3].

\section{The destined purpose}

Society is the ultimate backbone of this regimented universe. Each person has different social problems, which are the massive constrain to sustain. On the other hand, India is an overcrowded nation in all regards. So overpopulation is one of the prodigious problems not only to handle but to popularize the same from the point of view of its crucial democracy. As a real matter of the fact most of poor fellows do not come into the limelight. But that is absolutely desirable for them to perform and to manifest their societal charisma in style. That is going to highlight the national stature altogether. Therefore, the purpose of this article is to aware the common people and it shall have the most congruous glimpse about the present day scenario not only in national level, but also in an international level to rescue those needy bunch of people, they are the today's sunsets so far. This paper shall definitely rouse our CSR community to take the needful initiative for those deprived people and it shall help those communities for providing the sound finance and astounding footings to survive with words and wisdom. Only then the entire universe shall get of this huge quality deficiency and that will be truly reformed through an infinite hope to make all the precious resolutions for developing the existing infrastructure right from education to occupational magnificence in a befitting manner. On the other hand, their personality and the day-to-day attitude shall be entirely matured and reexecuted for the optimum cultural recognition of such an electrifying universe like this.

\section{Authors novelty and practical significance}

The author tried to entrench the utmost difficulties of socioeconomic challenges. Moreover, researchers do understand the fundamental needs of those poor fellows try to highlight the remedies in an elementary level not only for those needy people but for the entire society. As firm belief the entire universe should have the requisite revolution shortly. In other words, they need to develop the dogmatic infrastructure of this universe, which derives the global economy in all the regards.

At the same point of time each one of us must refine our life styles in a glorious manner. Their lifestyles along with the marvelous educational cameo shall affect both qualitative and quantitative metamorphosis in international context. Basically, people are aimed at an outstanding flow of different developing movements, such as education, operation, business development, employment, sports, academic research, personality development and so on.

Therefore, this paper shall be truly engaging and truly compelling to throw some light upon our communal development. People do have some immense talents but they do not have the real opportunities to execute at all in this competitive origin.

\section{Practical significance}

Magnanimous guidance. It is absolutely essential for each one of us, that only it shall be very engaging to form an absolute community, where we shall have the needful spirit to fabricate the solution through some glistening ideologies and implications.

Worthy scopes. It has some exceptional impacts upon those basic social tools such as behavior. It is going to be absolutely conducive for all of us to achieve a lot of wings. Besides that those needy people shall invariably be reorganized and they will be in well shape in style.

Security. It is one of the crucial objectives so far. Socioeconomic challenges are the unavoidable present day issue. Nevertheless, people shall have to have the purposeful solutions through their occupational dexterity at all. 


\section{Literature review}

The glimpse of this literature is to identify the destined social need of our national/international citizens. So that, they shall be getting rid off to overcome those challenges at all. So that, it shall be definitely very enriching for all of them to touch their sequential benchmark in their life. Moreover that shall give an astounding satisfaction to all of them not only to survive in a respectful manner but to flourish their entire potential to defend the socioeconomic challenges. On the other hand, each one of us should have an absolute expectation from the society. So all the challenges are equally very difficult and tricky to achieve. But they all need to be appreciated. This appreciation shall definitely inspire them for extracting some preventive measure within a short while. So it is absolutely riveting for each class to attain their requisite education first they must implement their scholastic brain to delete all the social challenges in style. So that, everybody shall have the histrionic release from the same and they shall be able to lead their life in an amicable manner.

In the same light they must form an absolute community segment, where they shall be able to discuss about the present day challenges. So that, different views shall be raised and that shall be evaluated accordingly. Moreover this communal decision shall be taken care of by government, so they shall be able to proceed with some congruous objectives, because their common motive are to restrict those challenges and social barriers respectively.

This community shall be maintained through some desirous people, who are aimed at some unavoidable social welfare and they shall be able to achieve those social constrains from the core of their best cognitive reflections. So the additional confidence will be definitely generated and it shall be automatically reflected upon the great societal dedication. This confidence is absolutely essential for generating a new resolution and must be regulated by the national leaders in a comprehensive style to make it an unblemished society.

\section{Discussions}

1. These challenges should be removed.

2. All wars should be stopped and the habit of adjustments must be immediately implemented.

3. The requisite ambitions should be promised and properly exhibited.

4. Leadership qualities should be empowered and properly generated in every aspect at all shortly.

5. Common people should have a clear envision to reach their social need and peaceful communal heaven in a very respectful manner.

\section{Socioeconomic celerity}

Each established society has some specific paradigm. So it should have the unstoppable cultural celerity in all regards. Otherwise the enchanted radiance of a society shall never be grown up. Moreover people shall never be involved with this. So they shall not be able to realize the socio economic status in this context.

Employment. It is an inestimable flow, which is absolutely needful for everybody to spark the economic status. In this regard Government shall have to take the massive initiative to provide employments as much as possible. As an emphatic reflection people shall have the sufficient finance and on the other hand each family shall have a sound financial affluence.

Participation. Leaders do have an eye-catching role out here to motivate each citizen of a nation. In the same light, leaders have to extract the best need out of them, which is very conducive for all of them to participate in any cultural magnificence in an irresistible manner. So that, they will be refined and they shall be able to generate confidence in them within a very short while.

Industrial strength. As far as the robust economic outflow is concerned, the government shall have the initiative to instigate the industry as much as possible. So it shall be fortunate enough for each citizen to get involved with this in a very reputable manner. Moreover each citizen shall be given some specified responsibilities to execute their performance and it will be really dogmatic for them to represent their organization with words and wisdom.

Formation of private sector. It is very omnipotent, as well. From the point of view of engagement it is really worthwhile for generating private sectors as well. So both private and government sector should enrich the occupational flow. As a matter of the fact, most of the people shall have the professional destiny without any behavioral conflict and misunderstanding. So the ratio of socioeconomic challenges will be really less shortly. 
Corruption. It should be stopped and erased from the society for ever. Then the social flow will have a special platform for the entire nation not only to evaluate people properly but to provide best societal peace in a respectful manner [5].

\section{Present day challenges}

Situational complexity. It is of the herculean challenges for a community leader, because they do have the great objective to win communal goal at all. In this regard they do face a lot of problems from the point of view of politics and the social giants. So they do convince through their utmost social policies in all the regards, which shall be eventually profitable to achieve the virtue of socioeconomy for a common welfare.

Environmental metamorphosis. It is one of the prime reasons over here. Leaders have been suffering different problems due to this sudden metamorphosis, because leaders maintain all the ancient policies and regulations to overcome the occupational virtuosity but everything has been changed. So as a result they try to adapt all the present day methodologies through versatile trainings.

Biased behavioral impact. Biasness is very harmful to continue any industrious initiative. Moreover it is next to impossible for a leader to evaluate any business environment. So they shall have to be really neutral here and shall be able to grab any quality person for contributing towards the harmless society. Societal splendor shall be absolutely magnificent in implementing this movement.

Overcrowded juncture. Leaders are really hopeless in this overcrowded platform of business and industry. They cannot assure the real beneficial space for developing the nation. So as per the requirement, they try to reduce the population strategically.

Anticorruption. It might discard the quality bunch of people for our national welfare. So leaders are extremely alert and watchful to fabricate an unvanquished community to fight against socioeconomic challenges in all regards.

Social practice. It largely depends on the standard of people. Leaders try to find that solid bunch, which is extremely agreeable for an industrious destiny. If it is so then it shall be truly easier to defend those up front challenges.

Effect of multilanguage. Leaders are very contemplative about the huge consequence of multilanguage, because each language has different significances altogether. That is why leaders try to formalize the common language of communication at least for fabricating an imperishable cultural synthesis irrespective of their mother tongue. So that, it shall have an astounding response for the comprehensive occupational hike.

Collision. It is absolutely harmful as far as socioeconomic growth is concerned. So leaders are extremely careful about that. Moreover they try to train their followers in such a manner as if socio economic pinnacle of those people is just the matter of time [2].

\section{Conclusion}

Socioeconomic challenges are the fundamental constrains for the national development. But as per the modern economical actuality and the utmost dexterity of our community leaders this are going to be one of the ravishing occupational confinements, where skilled people's empowerment is the superlative demand along with the introspective leaders and their priceless foresight, which shall be unquestionably the vintage of socioeconomic pride in our lifetime.

\section{References}

1. Contributions to socio-economic objectives. Retrieved from https://www.innovationpolicyplatform.org/content/contributions-socio-economic-objectives.

2. Davies Dan, Jindal-Snape Divya, Collier Chris, Digby Rebecca, Hay Penny and Howe Alan (2013). Creative learning environments in education - A systematic literature review, Thanking Skills and Creativity, 8, 80-91. Retrieved from http://www.sciencedirect.com/science/article/pii/S187118711200051X.

3. Frasquilho Diana, Matos Margarida Gaspar, Salonna Ferdinand, Guerreiro Diogo, Storti Claudia C., Gaspar Tania and Caldas-de-Almeida Jose M. (2015). Mental health outcomes in times of economic recession: a systematic literature review, BMC Public Health, PMCID: PMC4741013. Retrieved from https://www.ncbi.nlm.nih.gov/pmc/articles/PMC4741013/. 
4. Milan Wall (2000). Eight Challenges Facing Community Leaders. A Newsletter from the Center for Community Economic Development; Community, Natural Resource and Economic Development Programs, and University of Wisconsin-Extension, Cooperative Extension Service. Retrieved from https://www.aae.wisc.edu/pubs/cenews/docs/ce282.txt.

5. Parsons Jennifer, Edmeades Jeffrey, Kes Aslihan, Petroni Suzanne, Sexton Maggie, Wodon Quentin (2015). Economic Impacts of Child Marriage: A Review of the Literature. The Review of Faith \& International Affairs, 13(3), 12-22. Retrieved from http://www.tandfonline.com/doi/full/10.1080/ 15570274.2015.1075757.

6. Purnima Awasthi (2011). Socio-economic challenges and sustainable development in developing countries. Management Insight, 7(2), 56-63. Retrieved from http://www.inflibnet.ac.in/ojs/index.php/MI/article/view/932.

7. Socio Economic Problems in India. Retrieved from http://www.innovativelawcollege.com/socio-economics-problems.html.

8. Terri Williams. What Are Socioeconomic Issues? Retrieved from http://peopleof.oureverydaylife.com/socioeconomic-issues-7032.html. 